\title{
Collaboration of Nonlinear Control Strategy and Pitch Angle Control of DFIG Equipped Wind Turbine during all Operating Regions
}

\author{
Moussa Reddak, Abdelmajid Berdai, Ayoub Nouaiti, Vladimir Vlasenko \\ Laboratory of Energy and Electrical Systems (LESE) \\ Superior National School of Electricity and Mechanics (ENSEM) \\ Hassan II University of Casablanca, B.P 8118, Oasis, Casablanca, Morocco \\ Department of Electromechanics, Krivoy Rog National University, Krivoy Rog, Ukraine
}

\begin{abstract}
Wind energy has marked in these last decades a great growth view its interest that present. But this energy is entirely dependent on the wind flow which is random and uncertain in the nature, and which can exceed the rated wind speed. So, the wind turbine must be protected against mechanical overload and possible risk of damages. In this paper, a control strategy of wind turbine equipped with the doubly fed induction generator DFIG is proposed for different wind regions. The interest of this control strategy is to extract the maximum power at wind speed below the rated value. Otherwise its objective is to protect the wind turbine and maintain the active power when the wind speed is above the rated value. To achieve a fast response of active and reactive powers that are controlled by the rotor currents, a nonlinear control based on the backstepping strategy is suggested. The simulation results reveal a better tracking of the references, and exploitation of the wind turbine in different wind regions.
\end{abstract}

\section{Keywords}

Wind turbine, DFIG, control strategy, wind regions, backstepping strategy.

\section{INTRODUCTION}

The wind energy is currently one form of renewable energy, reproducible, potentially present and has a free pollution characteristic against the traditional energy sources. In addition, with technology progress, the cost of the wind energy has been reduced according to the motivations and the adoptions of financing for renewable energy installations since the last decade [1],[2].

In the first stage of wind energy development, the most wind farms are adopted the fixed speed technology. These turbines can only operate at a constant speed, which leads to an energy efficiency relatively low for all wind speeds. To improve their efficiencies, many modern wind turbines adopt the variable speed technology. Among the solutions of this later, the DFIG equipped the wind turbine presents many advantages compared to others [3],[4],[5]; the power converter is dimensioned for a portion of power transit estimated at $30 \%$ of the nominal power, therefore this configuration is rationally economic, and it can produce reactive power, helping, to play in results a role similar to conventional sources that are equipped by synchronous generators.

In variable speed, the pitch control becomes a vital technique in the wind turbines [6],[7],[8]. Generally, two control strategies are distinguished: At below the rated wind speed $(12 \mathrm{~m} / \mathrm{s})$, the speed regulator can continuously adjust the rotor speed at a level which the generator gives its maximum power, so the wind turbine efficiency will be increased. While in the case of wind speed above the rated value, the pitch angle must be regulated in order to maintain the extracted power at the rated value. In other words, the objectives of these two control strategies can be summarized in: Optimization of the output power below the rated wind speed, limitation of the power transited in the rotor as well as the loads fatigue reduction in the rotor shaft and mechanical components when the wind speed is above the rated speed [9],[10],[11].

This paper is organized as follows: After a few recall on the schematic diagram of the wind turbine control system, section II presents the model of the DFIG and turbine. Section III describes the control strategy of the wind turbine in different wind regions. The nonlinear integral backstepping control of speed and the rotor currents will be developed in section IV. The simulation results are depicted in section V. Finally conclusions are designated.

\section{SYSTEM MODELINGAND CONTROL STRATEGY DESCRIPTION 2.1 System modeling and control strategy description}

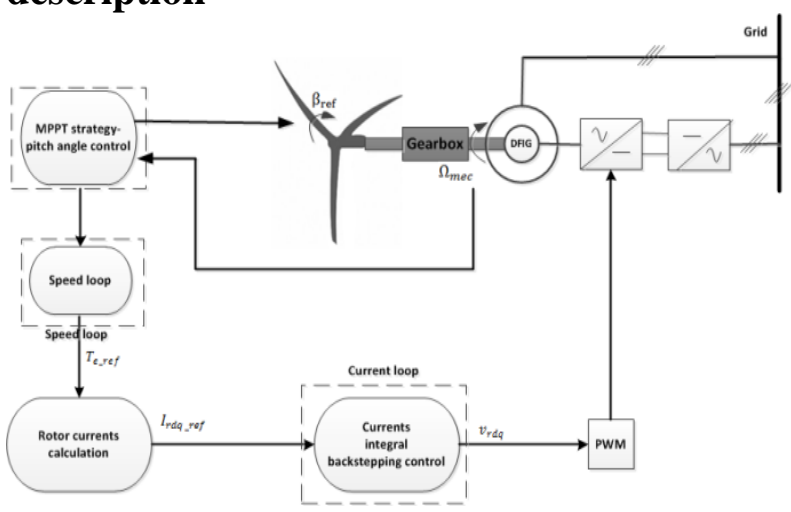

Fig 1: scheme of DFIG equipped wind turbine and the control system principle.

Figure 1 shows the schematic diagram of the DFIG equipped wind turbine and their control systems that are divided into two control units: The wind turbine and the DFIG control units. The first unit maintain the captured power at its rated value by applying the pitch angle control, it regulate the generator speed according to measured wind speed and the characteristic curve of speed-powers in order to optimize the extracted power during below rated wind speed, this block 
generates also the required reference torque needed for the active power control unit. In the other hand, in the DFIG control unit, the machine side converter controls the generated active and reactive powers.

\subsection{DFIG model}

In a d-q reference frame rotating at the arbitrary speed, the rotor and stator voltages of the DFIG are :

$\left\{\begin{array}{c}\mathrm{v}_{\mathrm{ds}}=\mathrm{R}_{\mathrm{s}} \mathrm{i}_{\mathrm{ds}}+\frac{\mathrm{d} \varphi_{\mathrm{ds}}}{\mathrm{dt}}-\omega \varphi_{\mathrm{qs}} \\ \mathrm{v}_{\mathrm{qs}}=\mathrm{R}_{\mathrm{s}} \mathrm{i}_{\mathrm{qs}}+\frac{\mathrm{d} \varphi_{\mathrm{qs}}}{\mathrm{dt}}+\omega \varphi_{\mathrm{ds}} \\ \mathrm{v}_{\mathrm{dr}}=\mathrm{R}_{\mathrm{r}} \mathrm{i}_{\mathrm{dr}}+\frac{\mathrm{d} \varphi_{\mathrm{dr}}}{\mathrm{dt}}-\left(\omega-\omega_{\mathrm{e}}\right) \varphi_{\mathrm{qr}} \\ \mathrm{v}_{\mathrm{qr}}=\mathrm{R}_{\mathrm{r}} \mathrm{i}_{\mathrm{qr}}+\frac{\mathrm{d} \varphi_{\mathrm{qr}}}{\mathrm{dt}}+\left(\omega-\omega_{\mathrm{e}}\right) \varphi_{\mathrm{dr}}\end{array}\right.$

The fluxes equations are given as

$\left\{\begin{array}{l}\varphi_{\mathrm{ds}}=\mathrm{L}_{\mathrm{s}} \mathrm{i}_{\mathrm{ds}}+\mathrm{Mi}_{\mathrm{dr}} \\ \varphi_{\mathrm{qs}}=\mathrm{L}_{\mathrm{s}} \mathrm{i}_{\mathrm{qs}}+\mathrm{Mi}_{\mathrm{qr}} \\ \varphi_{\mathrm{dr}}=\mathrm{L}_{\mathrm{r}} \mathrm{i}_{\mathrm{dr}}+\mathrm{MI}_{\mathrm{ds}} \\ \varphi_{\mathrm{qr}}=\mathrm{L}_{\mathrm{r}} \mathrm{i}_{\mathrm{qr}}+\mathrm{Mi}_{\mathrm{qs}}\end{array}\right.$

where all symbols have their habitual denotations and $\omega$ is the arbitrary rotating speed.

Active and reactive powers of the stator are:

$\left\{\mathrm{P}_{\mathrm{s}}=\mathrm{v}_{\mathrm{ds}} \mathrm{i}_{\mathrm{ds}}+\mathrm{v}_{\mathrm{qs}} \mathrm{i}_{\mathrm{qs}}\right.$

$\left\{\mathrm{Q}_{\mathrm{s}}=\mathrm{v}_{\mathrm{qs}} \mathrm{i}_{\mathrm{ds}}-\mathrm{v}_{\mathrm{ds}} \mathrm{i}_{\mathrm{qs}}\right.$

By aligning the stator flux to the $\mathrm{d}$-axis synchronous reference frame, neglecting the stator resistor, and substituting the flux equations into the voltage equations in (1), the dynamic of rotor current becomes [12]:

$\left\{\begin{array}{c}\frac{d i_{d r}}{d t}=\frac{1}{\sigma L_{r}}\left(v_{r d}-R_{r} i_{r d}-e_{q}\right) \\ \frac{d_{r q}}{d t}=\frac{1}{\sigma L_{r}}\left(v_{r q}-R_{r} i_{r q}-e_{d}-e_{\varphi}\right)\end{array}\right.$

With

$$
\left\{\begin{array}{c}
\mathrm{e}_{\mathrm{q}}=-\sigma \mathrm{L}_{\mathrm{r}} \omega_{\mathrm{r}} \mathrm{i}_{\mathrm{rq}} \\
\mathrm{e}_{\mathrm{d}}=\sigma \mathrm{L}_{\mathrm{r}} \omega_{\mathrm{r}} \mathrm{i}_{\mathrm{rd}} \\
\mathrm{e}_{\varphi}=\omega_{\mathrm{r}} \frac{\mathrm{M}}{\mathrm{L}_{\mathrm{s}}} \varphi_{\mathrm{s}}
\end{array}\right.
$$

Where $\omega_{\mathrm{r}}=\omega_{\mathrm{s}}-\omega_{\mathrm{e}}$

\subsection{Turbine model}

According to Betz theory, the mechanical power captured by the turbine is [13]:

$P_{a}=\frac{1}{2} \rho \pi R^{2} v^{3} C_{p}(\lambda, \beta)$

Its aerodynamic torque is given as:

$\mathrm{T}_{\mathrm{a}}=\frac{1}{2} \rho \pi \mathrm{R}^{3} \frac{\mathrm{C}_{\mathrm{p}}}{\lambda} \mathrm{v}^{2}$

With $\mathrm{v}$ is the wind speed, $\rho$ is the air density, $\mathrm{R}$ is the rotor radius, $\beta$ is the pitch angle, $C_{p}$ is the power coefficient, $\lambda$ is the tip-speed ratio.

And

$C_{p}(\lambda, \beta)=0.5176\left(\frac{116}{\lambda_{\mathrm{i}}}-0.4 \beta-5\right) e^{\left(\frac{-21}{\lambda_{\mathrm{i}}}+0.0068 \lambda\right)}$

With

$$
\frac{1}{\lambda_{i}}=\frac{1}{\lambda+0.08 \beta}-\frac{0.035}{\beta^{3}+1}
$$

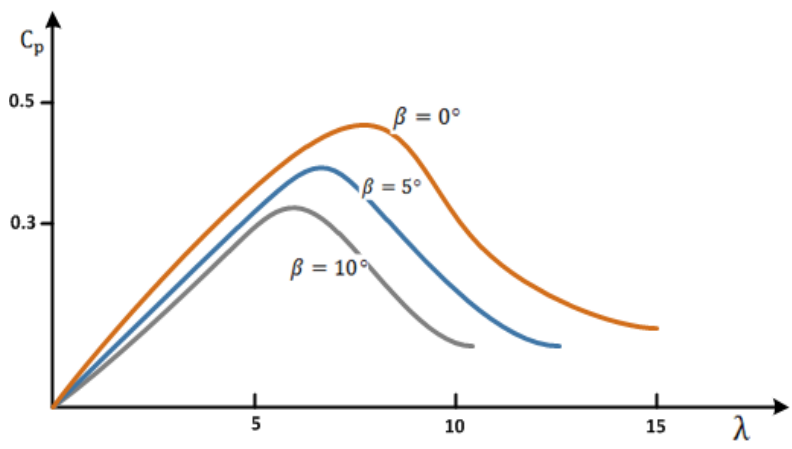

Fig 2: Curves of power coefficient-tip ratio speed for different pitch angle values.

The dynamic law of the wind turbine defines Eq:

$\mathrm{J}_{\text {eq }} \frac{\mathrm{d} \Omega}{\mathrm{dt}}=\mathrm{T}_{\mathrm{a}}-\mathrm{f}_{\mathrm{eq}} \Omega-\mathrm{T}_{\mathrm{e}}$

The tip speed ratio:

$\lambda=\frac{\mathrm{R} \Omega}{\mathrm{v}}$

\section{CONTROL STRATEGY DESCRIPTION}

\subsection{Control strategy for different wind speed regions}

There are three wind turbine operation regions which are defined by the wind speed; each operation region corresponds to a determined wind turbine power. Among these three regions, two regions for which the wind turbine control is necessary as long as the security limits are respected.

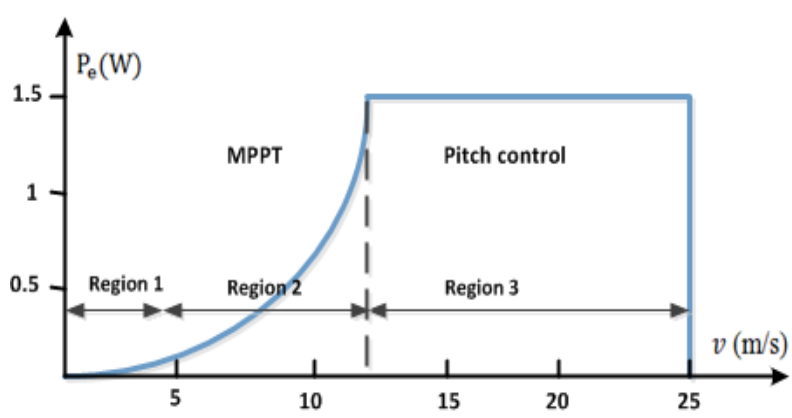

Fig 3: Extracted power versus wind speed.

- Region II (at below the rated wind speeds $(12 \mathrm{~m} / \mathrm{s})$ : As already mentioned, the wind turbine control in this region is designed to optimize the captured power by the turbine. The rotation speed of the turbine is controlled by the electromagnetic torque developed by the generator for achieving the optimal tip speed ratio $\lambda$ opt [14]. So the pitch angle is fixed $\left(\beta=0^{\circ}\right)$, and the power coefficient of the turbine will be at its maximum value $(\mathrm{Cpmax}=0.47)$. To obtain a fast response in this region, many nonlinear controllers have been adopted such as the backstepping strategy [15].

- Region III (In strong winds): When the wind speed exceeds its rated value, the control of blades pitch angle system is anticipated in favor of maintaining the produced electrical power at its rated value. 


\subsection{Turbine model}

The proportional integral controller (PI) is used to maintain the output power of the turbine at the rated value by adjusting the pitch angle, which can be considered as an effective solution in the presence of high wind speeds [16]. Fig. 3 shows a simplified PI controller that regulates the output in accordance with the error (e) between the generator rotor speed and its reference.

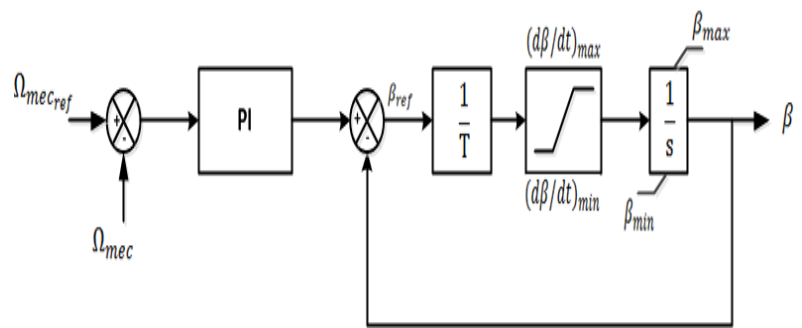

Fig 4: Pitch angle control based on PI controller.

This block generates the pitch angle that will limit the power coefficient and consequently the DFIG active power. To obtain a realistic response, a delay and pitch angle limitations are included in this block.

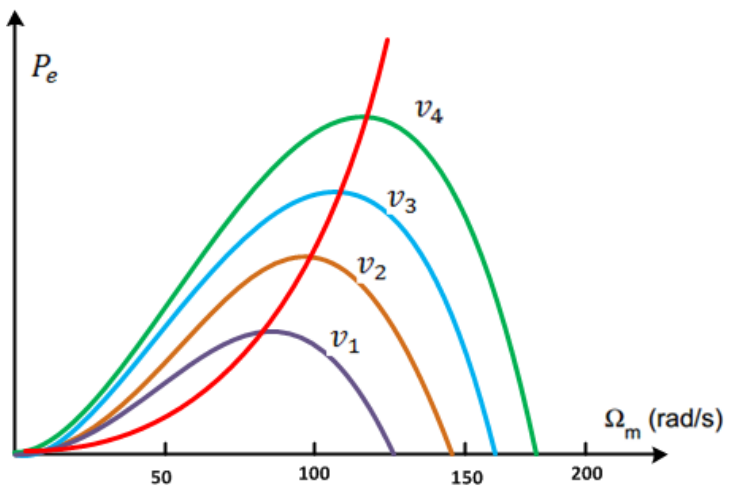

Fig 5: Electrical power versus mechanical generator speed for different wind speeds.

For each wind speed, there is a unique value of the DFIG rotor speed which gives a maximum power coefficient corresponding at a maximum extracted power (Fig.5). When the wind speed is below the rated value, the turbine should be operated in variable speed mode, and the DFIG rotation speed is adjusted in such a way that the maximum value of CP is reached. In this operation mode, the pitch control is disabled and the pitch angle $\beta$ is set to $0^{\circ}$. Otherwise, for wind speeds above the rated value, the rotor speed can no longer be increased in order to limit the generated power, thus the overload of the generator - converter system can be avoided. In this case, the pitch control is enabled to increase the pitch angle and the power extracted from the wind is restricted [7].

\section{SPEED AND CURRENTS}

\section{CONTROLLER'S SYNTHESIS}

The synthesis of the backstepping controllers is performed in two steps. In the first step, the speed loop is synthesized to regulate the mechanical rotor speed in order to track the reference value $\Omega$ mec-ref. Then, the second step is dedicated to synthesis the currents loop.

\subsection{Step1: Speed loop}

In the aim of designing the backstepping control law to ensure the speed tracking, the current reference must be calculated $\mathrm{f}$ to be considered as a virtual input of current loop.

The speed tracking error is:

$\mathrm{Z}_{\Omega}=\Omega_{\text {mec_ref }}-\Omega_{\text {mec }}+\mathrm{K}_{\omega} \int_{0}^{\mathrm{t}} \Omega_{\text {mec_ref }}-\Omega_{\mathrm{mec}} \mathrm{dt}$

$\omega_{\text {ref }}:$ The speed reference.

With $\mathrm{K}_{\omega} \int_{0}^{\mathrm{t}} \Omega_{\text {mec_ref }}-\Omega_{\text {mec }} \mathrm{dt}$ designate the integral term.

The error derivative is defined in $\mathrm{Eq}$ :

$\dot{\mathrm{Z}}_{\Omega}=\Omega_{\text {mec_ref }}-\Omega_{\text {mec }}+\mathrm{K}_{\Omega}\left(\Omega_{\text {mec_ref }}-\Omega_{\text {mec }}\right)$

The adopted Lyaponov function is:

$\mathrm{V}_{\Omega}=\frac{1}{2} \mathrm{Z}_{\Omega}^{2}$

Its time derivative:

$\dot{\mathrm{V}}_{\Omega}=\mathrm{Z}_{\Omega} \dot{\mathrm{Z}}_{\Omega}$

More precisely:

$$
\begin{aligned}
\dot{\mathrm{V}}_{\Omega}= & \mathrm{Z}_{\Omega}\left(\Omega_{\text {mec_ref }}-\frac{1}{\mathrm{Jeq}_{\text {eq }}} \mathrm{T}_{\text {mec }}+\frac{1}{\mathrm{Jeq}_{\text {eq }}} \mathrm{f}_{\text {eq }} \Omega_{\text {mec }}+\frac{1}{\mathrm{~J}_{\text {eq }}} \mathrm{T}_{\mathrm{e}}+\right. \\
& \left.\mathrm{K}_{\Omega}\left(\Omega_{\text {mec_ref }}-\Omega_{\text {mec }}\right)\right)
\end{aligned}
$$

To ensure a negative sign of this derivative, a term of $\mathrm{K}_{\Omega}^{\prime} \mathrm{Z}_{\Omega}$ is intercaled in Eq.14:

$$
\begin{gathered}
\dot{\mathrm{V}}_{\Omega}=\mathrm{Z}_{\Omega}\left(\mathrm{K}_{\Omega}^{\prime} \mathrm{Z}_{\Omega}+\Omega_{\mathrm{mec}_{\text {ref }}}-\frac{1}{\mathrm{~J}_{\mathrm{eq}}} \mathrm{T}_{\mathrm{mec}}+\frac{1}{\mathrm{Jeq}_{\mathrm{eq}}} \mathrm{f}_{\mathrm{eq}} \Omega_{\mathrm{mec}}+\right. \\
\left.\frac{1}{\mathrm{Jeq}_{\mathrm{eq}}} \mathrm{T}_{\mathrm{e}}+\mathrm{K}_{\Omega}\left(\Omega_{\mathrm{mec}_{\mathrm{ref}}}-\Omega_{\mathrm{mec}}\right)\right)-\mathrm{K}_{\Omega}^{\prime} \mathrm{Z}_{\Omega}{ }^{2}
\end{gathered}
$$

In this case, the reference electromagnetic torque is defined as:

$$
\begin{gathered}
\mathrm{T}_{\mathrm{e}_{-} \text {ref }}=\mathrm{T}_{\mathrm{a}}-\mathrm{f}_{\mathrm{eq}} \Omega_{\mathrm{mec}}-\mathrm{J}_{\text {eq }} \Omega_{\mathrm{mec} \_ \text {ref }}-\mathrm{J}_{\mathrm{eq}} \mathrm{K}_{\Omega}^{\prime} \mathrm{Z}_{\Omega}- \\
\mathrm{J}_{\mathrm{eq}} \mathrm{K}_{\Omega}\left(\Omega_{\mathrm{mec}_{\text {ref }}}-\Omega_{\mathrm{mec}}\right)
\end{gathered}
$$

The q-axis reference current is calculated as:

$$
\begin{gathered}
\mathrm{i}_{\text {rq_ref }}=-\frac{\mathrm{L}_{\mathrm{s}}}{\mathrm{p} \cdot \mathrm{M} . \varphi_{\mathrm{sd}}}\left(\mathrm{T}_{\mathrm{a}}-\mathrm{f}_{\mathrm{eq}} \Omega_{\mathrm{mec}}-\mathrm{J}_{\mathrm{eq}} \Omega_{\mathrm{mec}_{\mathrm{ref}}}-\mathrm{J}_{\mathrm{eq}} \mathrm{K}_{\Omega}^{\prime} \mathrm{Z}_{\Omega}-\right. \\
\left.\mathrm{J}_{\mathrm{eq}} \mathrm{K}_{\Omega}\left(\Omega_{\mathrm{mec}_{\text {ref }}}-\Omega_{\mathrm{mec}}\right)\right)
\end{gathered}
$$

Under Eq.15 and Eq.16, The time derivative Lyaponov function becomes:

$\dot{\mathrm{V}}_{\Omega}=-\mathrm{K}_{\Omega}^{\prime} \mathrm{Z}_{\Omega}{ }^{2}$

endorsing the asymptotic convergence of the generator mechanical speed.

\subsection{Step1: Currents loop}

\section{- $\mathrm{i}_{\mathrm{rq}}$ current loop}

Once the input virtual q-axis rotor current is well determined, an error of this current is defined to ensure its regulation:

$\mathrm{z}_{\mathrm{q}}=\mathrm{i}_{\text {rq_ref }}-\mathrm{i}_{\text {rq }}+\mathrm{K}_{\mathrm{q}} \int_{0}^{\mathrm{t}} \mathrm{i}_{\text {rq_ref }}-\mathrm{i}_{\text {rq }} \mathrm{dt}$

Otherwise:

$\mathrm{Z}_{\mathrm{q}}=\mathrm{i}_{\text {rq_ref }}-\mathrm{i}_{\text {rq }}+\mathrm{e}_{\text {irq }}$

The defined Lyaponv function in this step is: 
$\mathrm{V}_{\mathrm{q}}=\frac{1}{2} \mathrm{Z}_{\mathrm{q}}^{2}+\mathrm{V}_{\Omega}$

And we have:

$$
\begin{aligned}
\dot{\mathrm{V}}_{\Omega}= & \mathrm{Z}_{\Omega}\left(\mathrm{K}_{\Omega}^{\prime} \mathrm{Z}_{\Omega}+\Omega_{\mathrm{mec}_{\text {ref }}}-\frac{1}{\mathrm{Jeq}_{\mathrm{eq}}} \mathrm{T}_{\mathrm{mec}}+\frac{1}{\mathrm{Jeq}_{\mathrm{eq}}} \mathrm{f}_{\mathrm{eq}} \Omega_{\mathrm{mec}}+\right. \\
& \left.\frac{1}{\mathrm{Jeq}_{\mathrm{eq}}} \mathrm{p} \varphi_{\mathrm{s}} \frac{\mathrm{M}}{\mathrm{L}_{\mathrm{s}}} \mathrm{i}_{\mathrm{qr}}+\mathrm{K}_{\Omega}\left(\Omega_{\mathrm{mec}_{\mathrm{ref}}}-\Omega_{\mathrm{mec}}\right)\right)-\mathrm{K}_{\Omega}^{\prime} \mathrm{Z}_{\Omega}{ }^{2}
\end{aligned}
$$

Replacing $\mathrm{i}_{\mathrm{qr}}$ by its term defined in Eq.17, this derivative will be:

$$
\begin{aligned}
\dot{\mathrm{V}}_{\Omega}= & \mathrm{Z}_{\Omega}\left(\mathrm{K}_{\Omega}^{\prime} \mathrm{Z}_{\Omega}+\Omega_{\mathrm{mec}_{\text {ref }}}-\frac{1}{\mathrm{Jeq}_{\mathrm{eq}}} \mathrm{T}_{\mathrm{mec}}+\frac{1}{\mathrm{Jeq}_{\mathrm{eq}}} \mathrm{f}_{\text {eq }} \Omega_{\mathrm{mec}}+\right. \\
& \left.\frac{1}{\mathrm{~J}_{\mathrm{eq}}} \mathrm{p} \varphi_{\mathrm{s}} \frac{\mathrm{M}}{\mathrm{L}_{\mathrm{s}}}\left(\mathrm{i}_{\mathrm{rq}} \mathrm{ref}_{\mathrm{ref}}-\mathrm{Z}_{\mathrm{q}}+\mathrm{e}_{\mathrm{irq}}\right)+\mathrm{K}_{\Omega}\left(\Omega_{\mathrm{mec}_{\text {ref }}}-\Omega_{\mathrm{mec}}\right)\right)- \\
& \mathrm{K}_{\Omega}^{\prime} \mathrm{Z}_{\Omega}{ }^{2}
\end{aligned}
$$

So this derivative becomes:

$\dot{\mathrm{V}}_{\Omega}=-\mathrm{K}_{\Omega}^{\prime} \mathrm{Z}_{\Omega}^{2}+\frac{1}{\mathrm{~J}_{\mathrm{eq}}} \mathrm{p} \varphi_{\mathrm{s}} \frac{\mathrm{M}}{\mathrm{L}_{\mathrm{s}}} \mathrm{Z}_{\Omega} \cdot\left(-\mathrm{Z}_{\mathrm{q}}+\mathrm{e}_{\mathrm{irq}}\right)$

By taking into account the Eq.24, the dynamic of $\mathrm{V}_{\mathrm{q}}$ Lyaponov function would be defined as:

$\dot{\mathrm{V}}_{\mathrm{q}}=-\mathrm{K}_{\Omega}^{\prime} \mathrm{Z}_{\Omega}{ }^{2}+\mathrm{Z}_{\mathrm{q}}\left(-\frac{1}{\mathrm{~J}_{\mathrm{eq}}} \mathrm{p} \varphi_{\mathrm{s}} \frac{\mathrm{M}}{\mathrm{L}_{\mathrm{s}}} \mathrm{Z}_{\Omega}+\dot{\mathrm{Z}}_{\mathrm{q}}\right)+\frac{1}{\mathrm{~J}_{\mathrm{eq}}} \mathrm{p} \varphi_{\mathrm{s}} \frac{\mathrm{M}}{\mathrm{L}_{\mathrm{s}}} \mathrm{Z}_{\Omega} \mathrm{e}_{\text {irq }}$ (25)

The term $\frac{1}{\mathrm{~J}_{\mathrm{eq}}} \mathrm{p} \varphi_{\mathrm{s}} \frac{\mathrm{M}}{\mathrm{L}_{\mathrm{s}}} \mathrm{Z}_{\Omega} \mathrm{e}_{\text {irq }}$ would be considered null.

To satisfy the condition $\dot{\mathrm{V}}_{\mathrm{q}} \leq 0$ (asymptotic convergence), the Eq.26 is imposed:

$-\frac{1}{\mathrm{~J}_{\mathrm{eq}}} \mathrm{p} \varphi_{\mathrm{s}} \frac{\mathrm{M}}{\mathrm{L}_{\mathrm{s}}} \mathrm{Z}_{\Omega}+\dot{\mathrm{Z}}_{\mathrm{q}}=-\mathrm{K}^{\prime}{ }_{\mathrm{q}} \mathrm{Z}_{\mathrm{q}}$

With $\mathrm{K}_{\mathrm{q}}^{\prime}$ is a positive parameter.

In this case, $\dot{\mathrm{V}}_{\mathrm{q}}$ is defined as:

$\dot{\mathrm{V}}_{\mathrm{q}}=-\mathrm{K}_{\Omega}^{\prime} \mathrm{Z}_{\Omega}{ }^{2}-\mathrm{K}^{\prime}{ }_{\mathrm{q}} \mathrm{Z}_{\mathrm{q}}{ }^{2}$

Finding now the $v_{\text {rd }}$ control law

$-\frac{1}{\mathrm{~J}_{\mathrm{eq}}} \mathrm{p} \varphi_{\mathrm{s}} \frac{\mathrm{M}}{\mathrm{L}_{\mathrm{s}}} \mathrm{Z}_{\Omega}+\mathrm{r}_{\mathrm{rq}_{-} \text {ref }}-\mathrm{r}_{\mathrm{rq}} \cdot \mathrm{e}_{\mathrm{irq}} \cdot \mathrm{K}_{\mathrm{q}}^{\prime} \mathrm{Z}_{\mathrm{q}}$

And by replacing $\mathrm{l}_{\mathrm{rq}}$ by its terms of the nonlinear DFIG model, the control law of $\mathrm{v}_{\mathrm{rq}}$ is the following:

$$
\begin{gathered}
\mathrm{v}_{\mathrm{rq}}=\sigma \mathrm{L}_{\mathrm{r}}\left(\mathrm{i}_{\mathrm{rq}_{r} \text { ref }}+\mathrm{K}_{\mathrm{q}}\left(\mathrm{i}_{\mathrm{rq}_{r} \text { ref }}-\mathrm{i}_{\mathrm{rq}}\right)-\mathrm{K}_{\mathrm{q}^{\prime}} \mathrm{Z}_{\mathrm{q}}\right)+\mathrm{R}_{\mathrm{r}} \mathrm{i}_{\mathrm{rq}}+\mathrm{e}_{\mathrm{d}}+ \\
\mathrm{e}_{\varphi}-\frac{1}{\mathrm{Jeq}_{\mathrm{eq}}} \mathrm{p} \varphi_{\mathrm{s}} \frac{\mathrm{M}}{\mathrm{L}_{\mathrm{s}}} \mathrm{Z}_{\Omega}
\end{gathered}
$$

- $\mathrm{i}_{\text {rd }}$ current loop

Considering the d-axis current error:

$\mathrm{Z}_{\mathrm{d}}=\mathrm{i}_{\text {rd_ref }}-\mathrm{i}_{\text {rd }}+\mathrm{K}_{\mathrm{d}} \int_{0}^{\mathrm{t}} \mathrm{i}_{\text {rd_ref }}-\mathrm{i}_{\text {rd }} \mathrm{dt}$

And the following Lyaponov function:

$\mathrm{V}_{\mathrm{d}}=\frac{1}{2} \mathrm{Z}_{\mathrm{d}}^{2}$

Its dynamic:

$\dot{\mathrm{V}}_{\mathrm{d}}=\mathrm{Z}_{\mathrm{d}} \dot{\mathrm{Z}}_{\mathrm{d}}$

If $Z_{d}$ term is consideredr in this equation, the Laponov time derivative $\dot{V}_{\mathrm{d}}$ becomes:

$$
\begin{gathered}
\dot{\mathrm{V}}_{\mathrm{d}}=\mathrm{Z}_{\mathrm{d}}\left(\left(\mathrm{i}_{\text {rd_ref }}-\frac{1}{\sigma \mathrm{L}_{\mathrm{r}}} \mathrm{v}_{\mathrm{rd}}+\frac{1}{\sigma \mathrm{L}_{\mathrm{r}}} \mathrm{R}_{\mathrm{r}} \mathrm{i}_{\text {rd }}+\frac{1}{\sigma \mathrm{L}_{\mathrm{r}}} \mathrm{e}_{\mathrm{q}}\right)+\right. \\
\left.\mathrm{K}_{\mathrm{d}}\left(\mathrm{i}_{\text {rd_ref }}-\mathrm{i}_{\text {rd }}\right)+\mathrm{K}^{\prime}{ }_{\mathrm{d}} \mathrm{Z}_{\mathrm{d}}\right)-\mathrm{K}_{\mathrm{d}}{ }_{\mathrm{d}} \mathrm{Z}_{\mathrm{d}}{ }^{2}
\end{gathered}
$$

By taking into account the $\mathrm{v}_{\text {rd }}$ control law:

$\mathrm{v}_{\mathrm{rd}}=\sigma \mathrm{L}_{\mathrm{r}}\left(\mathrm{i}_{\text {rd_ref }}+\mathrm{K}_{\mathrm{d}}\left(\mathrm{i}_{\mathrm{rd} \_ \text {ref }}-\mathrm{i}_{\text {rd }}\right)+\mathrm{K}_{\mathrm{d}}^{\prime} \mathrm{Z}_{\mathrm{d}}\right)+\mathrm{R}_{\mathrm{r}} \mathrm{i}_{\mathrm{rd}}+\mathrm{e}_{\mathrm{q}}$ (34)

The condition of asymptotic convergence is then given by the equation

$\dot{V}_{d}=-K^{\prime}{ }_{d} Z_{d}^{2}$

\section{SIMULATION RESULTS}

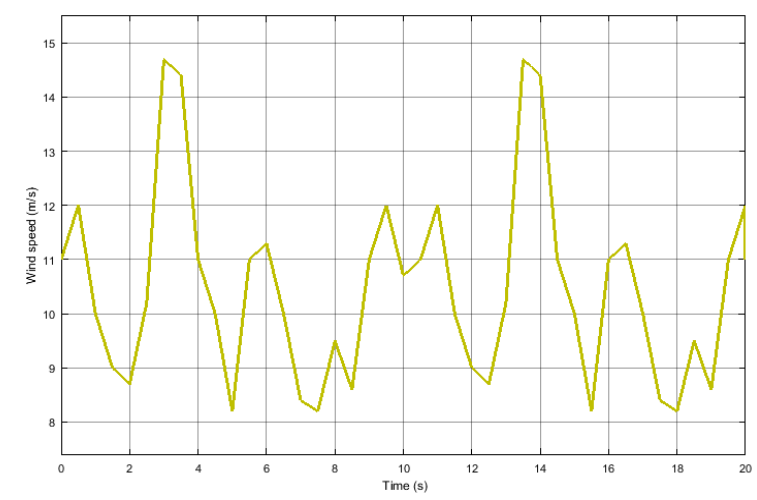

Fig 6: Wind speed reflecting different regions.

To validate the wind turbine control system, a wind profile bounded between 4 and $15 \mathrm{~m} / \mathrm{s}$ is applied to treat the different wind regions, by taking into account that the speed of $12 \mathrm{~m} / \mathrm{s}$ is the rated speed (Fig.6).

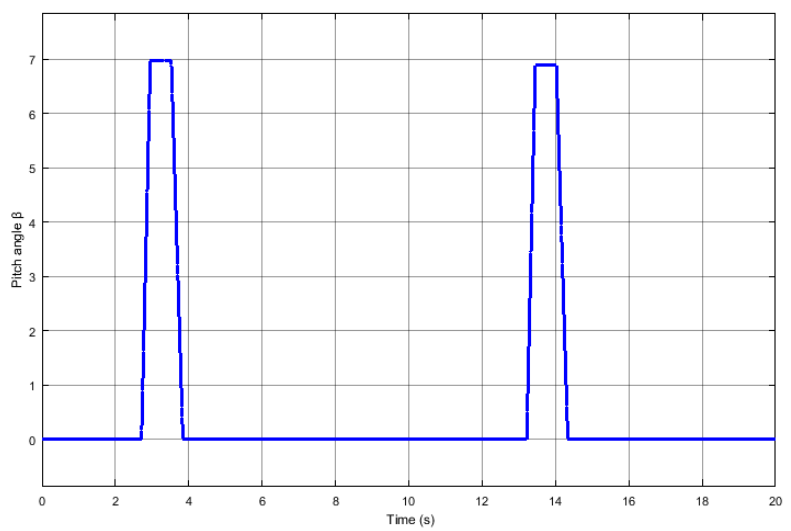

Fig 7: Pitch angle variation under the applied wind speed.

Figure 7 shows the blades pitch angle variations. In the case of the wind speed below the rated speed, the pith angle is set to $0^{\circ}$ as a minimum value in the aim to extract the maximum power (region II). However, the produced power is maintained at its rated value by varying the pitch angle when the wind speed exceeds the rated speed (region III). 


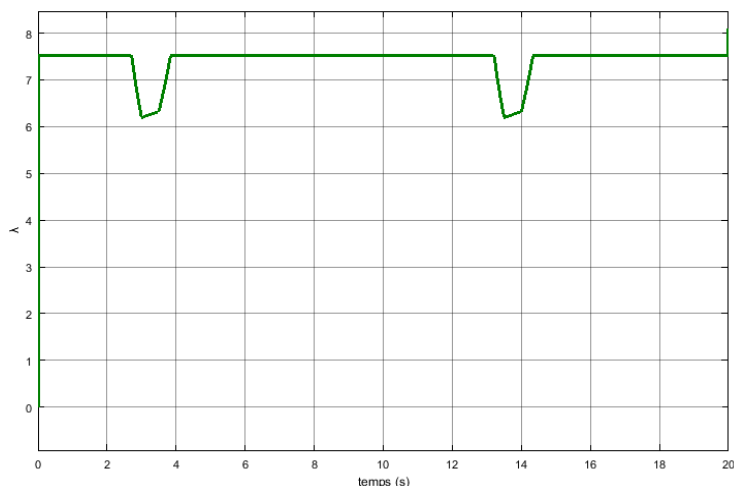

Fig 8: Tip speed ratio.

As is shown in Figure 8, the tip speed ratio maintains its optimum value in the region II, while in the region III, it decreases because the wind speed is increased and the mechanical speed of the generator is limited.

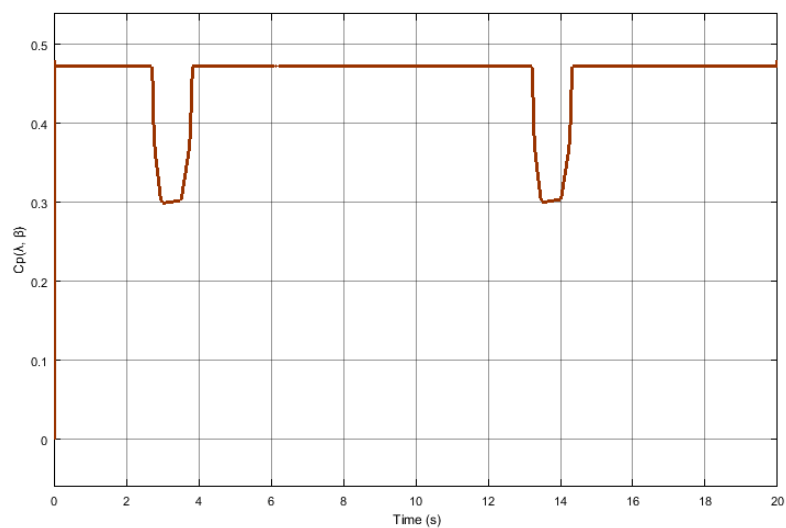

Fig 9: Power coefficient under the applied wind speed.

Figure 9 shows the power coefficient in the two operating wind regions; this coefficient is set to its nominal value in the region II to generate the maximum power under mechanical speed control. But in the region III, this coefficient is decreased due the variations of the tip speed ratio $\lambda$ and the pitch angle $\beta$.

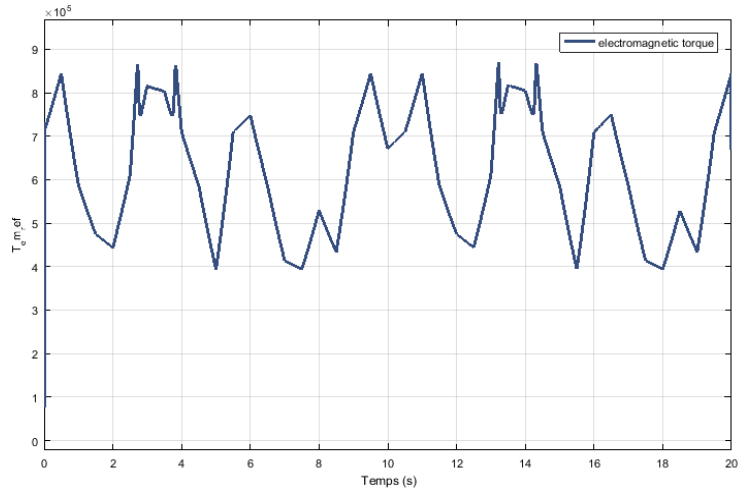

Fig 10: Developed electromagnetic torque.

The electromagnetic torque developed by DFIG is shown in figure 10. It can be noted that this torque regulate the mechanical speed to achieve the maximum power in region II, and it is limited in the region III to protect the DFIG-wind turbine from load fatigue on the rotor shaft.

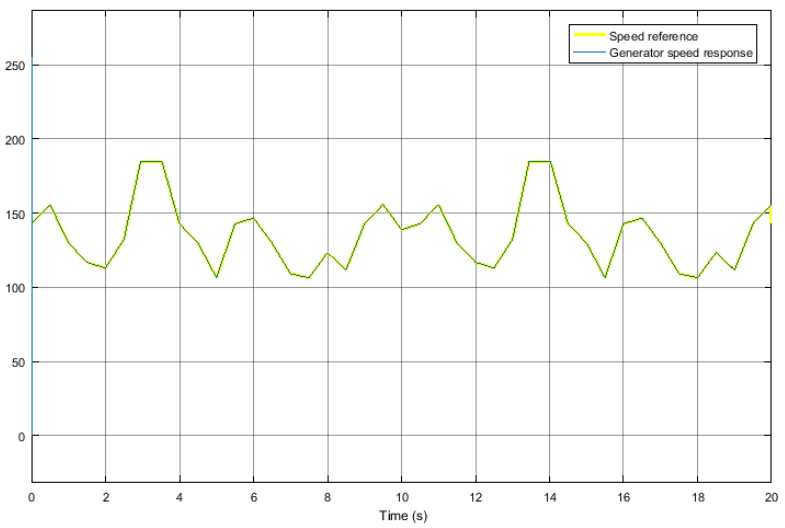

Fig 11: DFIG speed response.

Figure 11 illustrates the rotor generator speed response using the backstepping control strategy. It can be pointed out that there is a better speed reference tracking, confirming the effectiveness of this control strategy.

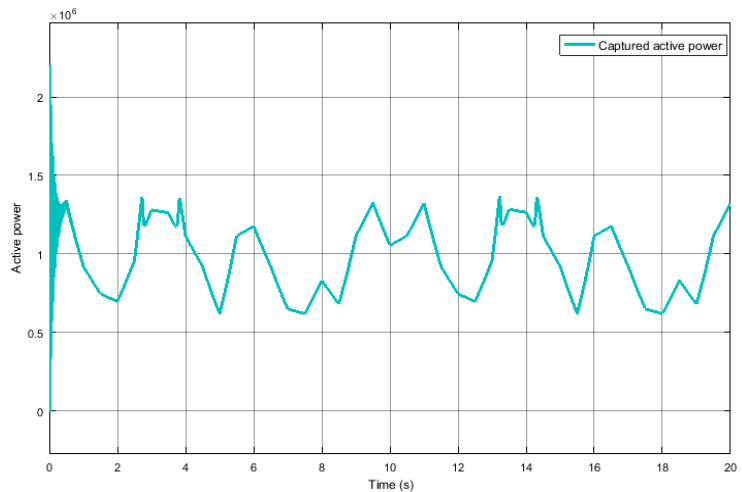

Fig 12: DFIG active power.

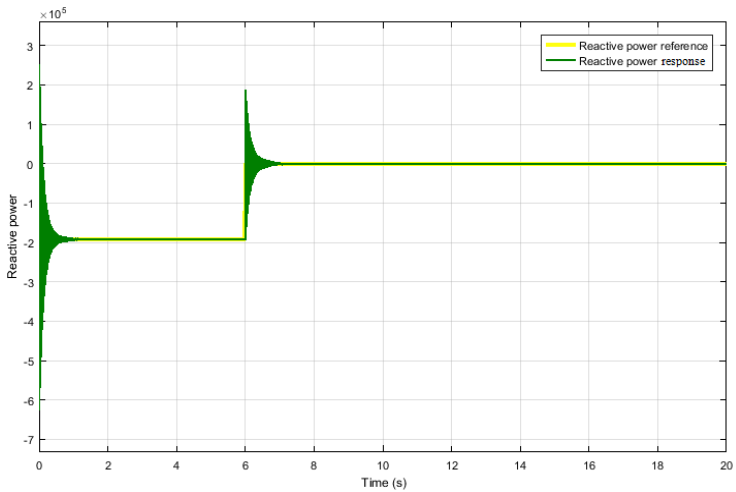

Fig 13: DFIG reactive power.

Figure 12 shows the active power evolution, this power is optimal at the wind speed below the rated value $(12 \mathrm{~m} / \mathrm{s})$, and it is limited when the wind speed is above its nominal value.

Figure 13 shows the response of generated DFIG reactive power. Two control strategy are mentioned; between $t=0 \mathrm{~s}$ and $\mathrm{t}=4 \mathrm{~s}$, the DFIG provide a portion of reactive power, and between $\mathrm{t}=4$ to $\mathrm{T}=20 \mathrm{~s}$, the control strategy in this interval impose a unitary power factor by applying a reactive power of $(\mathrm{Qref}=0)$. It can be noted that the nonlinear backstepping controller ensures a good tracking of the reactive power reference and a good decoupling powers, so a good power factor correction. 


\section{CONCLUSION}

This paper presents a new and efficient control strategy proposed for a wind turbine-DFIG system; this control strategy allows the turbine to remain production in the two wind speeds regions (Regions II and III).

It can be noted that the integral backstepping control strategy has well regulate the mechanical speed of the generator, which easily allowed alteration from region II to region III. The electromagnetic torque has been limited in order to protect the wind turbine system; also the generated active power has been well maintained at wind speed above the rated value (region III).

Among scopes of our work is the use of this control strategy to deal with grid faults.

\section{APPENDIX}

The simulations have been implemented using these parameters:

DFIG: $\mathrm{P}=1.5 \mathrm{MW}, \mathrm{p}=2, \mathrm{M}=4.41(\mathrm{mH}), \mathrm{Rs}=2(\mathrm{~m} \Omega), L_{s}=$ $6.01(\mathrm{mH}), L_{r}=4.451, \mathrm{~J}=4.1 .10^{4}$ (Turbine-DFIG).

Turbine: $\mathrm{R}=38, \mathrm{f}=0.2, \mathrm{G}=90$.

Gain of the controllers: $K_{d}=50, K_{q}=100, K_{\Omega}=70$ $\mathrm{K}_{\Omega}^{\prime}=2.10^{4}, \mathrm{~K}_{\mathrm{d}}^{\prime}=8.10^{3}, \mathrm{~K}_{\mathrm{q}}^{\prime}=4.10^{3}$

\section{REFERENCES}

[1] J. G. Cardoso, I. R. S. Casella, A. J. S. Filho, F. F. Costa, and C. E. Capovilla, "SCIG wind turbine wireless controlled using morphological fi ltering for power quality enhancement," Renew. Energy, vol. 92, pp. 303$311,2016$.

[2] L. Meegahapola, T. Littler, and S. Perera, "Electrical Power and Energy Systems Capability curve based enhanced reactive power control strategy for stability enhancement and network voltage management," Int. J. Electr. POWER ENERGY Syst., vol. 52, pp. 96-106, 2013.

[3] M. J. Zandzadeh and A. Vahedi, "Electrical Power and Energy Systems Modeling and improvement of direct power control of DFIG under unbalanced grid voltage condition," Int. J. Electr. Power Energy Syst., vol. 59, pp. $58-65,2014$.

[4] P. Zhou, S. Member, Y. He, S. Member, and D. Sun, "Improved Direct Power Control of a DFIG-Based Wind Turbine During Network Unbalance," vol. 24, no. 11, pp. 2465-2474, 2009.

[5] M. A. A. Rani, C. Nagamani, and G. S. Ilango, "A versatile method for computation of power pulsations in
DFIG under grid imperfections," Renew. Energy, vol. 88, pp. 143-153, 2016

[6] M. A. Chowdhury, N. Hosseinzadeh, and W. Shen, "Fuzzy logic systems for pitch angle controller for smoothing wind power fluctuations during below rated wind incidents," pp. 1-7, 2011.

[7] M. Quan, F. Grimaccia, S. Leva, M. Mussetta, and E. Ogliari, "Pitch angle control using hybrid controller for all operating regions of SCIG wind turbine system," Renew. Energy, 2014.

[8] T. Senjyu, R. Sakamoto, S. Member, and N. Urasaki, "Output Power Leveling of Wind Turbine Generator for All Operating Regions by Pitch Angle Control," vol. 21, no. 2, pp. 467-475, 2006.

[9] Y. Lei, A. Mullane, G. Lightbody, and R. Yacamini, "Modeling of the Wind Turbine With a Doubly Fed Induction Generator for Grid Integration Studies," vol. 21, no. 1, pp. 257-264, 2006.

[10] A. Hwas and R. Katebi, Wind Turbine Control Using PI Pitch Angle Controller, vol. 45, no. 3. IFAC, 2008.

[11] J. Zhang, M. Cheng, Z. Chen, and X. Fu, "Pitch Angle Control for Variable Speed Wind Turbines," no. April, pp. 2691-2696, 2008.

[12] A. B. Moreira, T. A. S. Barros, V. S. C. Teixeira, and E. Ruppert, "Power control for wind power generation and current harmonic fi ltering with doubly fed induction generator," Renew. Energy, vol. 107, pp. 181-193, 2017.

[13] B. Yang, L. Jiang, L. Wang, W. Yao, and Q. H. Wu, "Electrical Power and Energy Systems Nonlinear maximum power point tracking control and modal analysis of DFIG based wind turbine," vol. 74, pp. 429436, 2016.

[14] V. Rama, R. Rudraraju, C. Nagamani, and G. S. Ilango, "Electrical Power and Energy Systems A control scheme for improving the efficiency of DFIG at low wind speeds with fractional rated converters," Int. J. Electr. Power Energy Syst., vol. 70, pp. 61-69, 2015.

[15] A. Moussa REDDAK, Berdai and A. B. Anass Gourma, "Integral Backstepping Control based Maximum Power Point Tracking strategy for Wind Turbine systems driven DFIG," in nd International Conference on Electrical and Information Technologies ICEIT'20 16 Integral, 2016.

[16] M. A. Chowdhury, N. Hosseinzadeh, and W. X. Shen, "Smoothing wind power fl uctuations by fuzzy logic pitch angle controller," Renew. Energy, vol. 38, no. 1, pp. 224-233, 2012 